\title{
Does lipid-lowering medication improve cardiac sympathetic nerve integrity?
}

\author{
Rudolf A. Werner, MD, ${ }^{\mathrm{a}}$ James T. Thackeray, PhD, ${ }^{\mathrm{a}}$ and Frank M. Bengel, $\mathrm{MD}^{\mathrm{a}}$ \\ a Department of Nuclear Medicine, Hannover Medical School, Hannover, Germany
}

Received Aug 22, 2019; accepted Aug 22, 2019

doi:10.1007/s12350-019-01883-w

\section{See related article, pp. 1449-1457}

As evidenced by the prospective "'AdreView Myocardial Imaging for Risk Evaluation in Heart Failure (ADMIRE-HF)' trial, the catecholamine analogue radiotracer 123I-metaiodobenzylguanidine (123ImIBG) holds the potential for risk stratification among high-risk individuals with severely impaired cardiac function. ${ }^{1}$ Its prognostic performance is based on semiquantitative analysis, e.g. by calculating a heart-to-mediastinum ratio (HMR) on 4-hour delayed planar images, whereby patients below a certain threshold are at increased risk to experience any cardiac event. As a complementary measure, increased myocardial washout rate, which also considers background subtraction, is also associated with a worse outcome. ${ }^{1}$ Notably, the concept of assessing cardiac nerve integrity by 123ImIBG scintigraphy to identify high-risk congestive heart failure (CHF) patients has been further expanded by Nakajima and coworkers. ${ }^{2}$ Integrating the amount of denervated myocardium by 123I-mIBG scans and clinical parameters, dedicated 2- and 5-year mortality risk estimations charts could be provided, which allow for a more flexible short- and long-term management. ${ }^{2}$ In patients with acute myocardial infarction (MI), a simultaneous assessment of cardiac innervation and perfusion/viability has established that regional

Funding This project was supported by PRACTIS - Clinician Scientist Program of Hannover Medical School, funded by the German Research Foundation (DFG, ME 3696/3-1, RAW). This work was funded by the German Research foundation, through the research group KFO311 (FMB).

Reprint requests: Rudolf A. Werner, MD, Department of Nuclear Medicine, Hannover Medical School, Hannover, Germany; werner.rudolf@mh-hannover.de

J Nucl Cardiol 2021;28:1458-60.

1071-3581/\$34.00

Copyright (C) 2020 American Society of Nuclear Cardiology. sympathetic neuronal damage exceeds the area of hypoperfused tissue. ${ }^{3}$ Thus, sympathetic neurons appear to be more susceptible to ischemic injury than cardiomyocytes, which may help in identifying (pro)arrhythmic, denervated but viable areas-at-risk, such as the infarct borderzone. ${ }^{4,5}$ Given its incremental value in outcome prediction, studies in recent years have also investigated the complementary benefit of cardioprotective medication on the cardiac sympathetic nervous system (SNS) in combination with the overall ventricular performance among CHF patients. ${ }^{6-8}$

The prescription of statins (3-hydroxy-3-methylglutaryl-coenzyme A reductase inhibitors) is endorsed by current guidelines of the American College of Cardiology and American Heart Association. ${ }^{9}$ In patients with history of MI, high-intensity statins should be initiated which leads to significant reduction of cardiac events for primary and secondary prevention..$^{9}$ As such, a recently published meta-analysis of the Cholesterol Treatment Trialists' (CTT) Collaboration, enrolling 170,000 participiants in 26 randomized trials, reported that a reduction of the low-density lipoprotein (LDL) cholesterol by 2-3 $\mathrm{mmol} / \mathrm{L}$ lowers the risk of heart attack, revascularization or ischemic stroke by approximately $40-50 \% .{ }^{10}$ In addition, an extensive body of evidence supports the modulatory effect of statin therapy on the cardiac SNS and attenuation of left ventricular remodeling, ${ }^{11,12}$ predominantly driven by inhibition of central angiotensin II signaling and the superoxide pathway. ${ }^{13}$ In the present issue of the Journal of Nuclear Cardiology, Takahashi and coworkers investigated the impact of statins on cardiac nerve integrity derived by 123I-mIBG scintigraphy. A propensity-matched analysis was conducted to correct for selection bias, and 30 individuals with ST-segment elevation MI (STEMI) treated with statin therapy were compared to $30 \mathrm{MI}$ patients without statin therapy. Following coronary angioplasty, clinical characteristics such as age, gender or recanalization times were comparable between both groups. However, in cardiac 123I-mIBG scans 
conducted 3 weeks after MI, the statin group showed significantly higher delayed HMR (along with a reduced washout rate), reflecting improved cardiac nerve integrity, compared to the non-statin group. While not significant, this improvement in cardiac nerve integrity in the statin group was paralleled by a slight increase of LVEF derived by echocardiography performed at baseline and 3 weeks later. In addition, the plasma procollagen type III amino terminal peptide (PIIINP) was investigated, which serves as a biomarker for myocardial fibrosis in patients suffering from CHF. Notably, the delta of PIIINP (derived by blood values at baseline and 3 weeks after treatment) was lower in the statin group, which is also associated with a better outcome. ${ }^{14}$ The authors concluded that statin therapy improves cardiac nerve function in patients with recent STEMI, which in turn may attenuate ventricular remodeling and cardiac fibrosis.

Takahashi and colleagues shed light on the potential modulatory effect on cardiac nerve integrity of a frequently prescribed drug in coronary artery disease. ${ }^{15}$ From a clinical perspective, 123I-mIBG could be used to identify high-risk individuals who may most benefit from HMG-CoA reductase inhibition via statins. However, side effects of this drug are rather rare and the most serious adverse event associated with statins is a potentially life-threating rhabdomyolysis, with an incidence of $<1 / 1000$ patients treated. ${ }^{16}$ Given its high safety profile and documented efficacy, statins are one of the most prescribed drugs in the United States, and the most recent guidelines for lipid-lowering therapy has also substantially increased the number of patients eligible for statins. ${ }^{9,17}$ Thus, while the present study corroborates the beneficial effects of this treatment on the cardiac nervous system, it remains debatable whether 123I-mIBG is a useful tool to decide whether statins should be prescribed (i.e. in the vast majority of subjects, it will be prescribed anyway). The retrospective analysis also warrants further confirmation. First, although a propensity score matching both groups has been conducted, it remains unclear why those patients not treated with statins were not eligible for such lipid-lowering medication (either at the beginning of the study or during follow-up). Thus, a selection bias cannot be definitively ruled out, as the potential for an improved cardiac nerve integrity may have been per se lower in this particular cohort. Second, a more careful design of future studies is needed, e.g. by performing a baseline 123I-mIBG scan closer to the time of the infarct, which would also verify whether differences in both groups pre-existed. Third, a clear cause and effect relationship cannot be derived from the present data, as the improvement of the SNS could also be caused by either improvement in perfusion or function, which could impact the HMR. In addition, long-term outcome data, e.g. by LVEF assessments at delayed time-points would further clarify the underlying effect of statins on cardiac nerve integrity.

In clinical practice, there remains a substantial percentage of patients which is statin intolerant, ${ }^{18}$ and the pharmacologic options for those individuals has been recently expanded by the proprotein convertase subtilisin kexin type 9 inhibitors (PCSK9i), which facilitate degradation of hepatocyte LDL receptor. ${ }^{19}$ Studies such as of Takahashi and colleagues may lay the groundwork to assess cardiac nerve integrity in patients treated with PCSK9i as well, which may provide further insights into the beneficial effects of such novel drugs, e.g. to assess whether PCSK9i alone (or in combination with statins) is more beneficial for the cardiac SNS and LV performance. For instance, an 123I-mIBG scan prior to initiation of PCSK9i may be useful to identify appropriate candidates for such novel and expensive therapies and to differentiate between responders and non-responders. ${ }^{17,20}$ However, such an approach would be preferably performed with dedicated myocardial SNS positron emission tomography radiotracers, such as $11 \mathrm{C}$ hydroxyephedrine, 18F-LMI1195, 18F-fluorohydroxyphenethylguanidines, or the recently introduced $18 \mathrm{~F}$ AF78. ${ }^{21-26}$ These compounds have been advocated to allow for a more thorough evaluation of the cardiac nervous system, e.g. by assessing regional heterogeneity, such as denervation in the viable border zone of an infarct, instead of a more global assessment of cardiac nerve integrity using 123I-mIBG scintigraphy. ${ }^{27}$

Taken together, Takahashi and colleagues showed that currently prescribed lipid-lowering medication may have an impact on myocardial SNS, which may attenuate cardiac ventricular remodelling, but the present findings may rather not substantially influence decisionmaking in clinical practice. However, future studies may investigate whether SNS molecular imaging of the heart may hold the potential to identify treatment responders of novel and expensive lipid-lowering medication, preferably in subjects which are intolerant to current statin treatment.

\section{Disclosure}

Rudolf A. Werner, James T. Thackeray, and Frank M. Bengel have no conflict of interest to declare.

\section{References}

1. Jacobson AF, Senior R, Cerqueira MD, Wong ND, Thomas GS, Lopez VA et al. Myocardial iodine-123 meta-iodobenzylguanidine imaging and cardiac events in heart failure. Results of the 
prospective ADMIRE-HF (AdreView Myocardial Imaging for Risk Evaluation in Heart Failure) study. J Am Coll Cardiol 2010;55:2212-21.

2. Nakajima K, Nakata T, Matsuo S, Jacobson AF. Creation of mortality risk charts using $123 \mathrm{I}$ meta-iodobenzylguanidine heartto-mediastinum ratio in patients with heart failure: 2- and 5-year risk models. Eur Heart J Cardiovasc Imaging 2016;17:1138-45.

3. Simoes MV, Barthel P, Matsunari I, Nekolla SG, Schomig A, Schwaiger M, et al. Presence of sympathetically denervated but viable myocardium and its electrophysiologic correlates after early revascularised, acute myocardial infarction. Eur Heart J 2004;25:551-7.

4. Werner RA, Maya Y, Rischpler C, Javadi MS, Fukushima K, Lapa $\mathrm{C}$, et al. Sympathetic nerve damage and restoration after ischemiareperfusion injury as assessed by (11)C-hydroxyephedrine. Eur J Nucl Med Mol Imaging 2016;43:312-8.

5. Caobelli F. What future for the myocardial sympathetic innervation imaging? Eur J Nucl Med Mol Imaging 2017;44:2299-301.

6. Kasama S, Toyama T, Kumakura H, Takayama Y, Ichikawa S, Suzuki T, et al. Effect of spironolactone on cardiac sympathetic nerve activity and left ventricular remodeling in patients with dilated cardiomyopathy. J Am Coll Cardiol 2003;41:574-81.

7. Kasama S, Toyama T, Kumakura H, Takayama Y, Ichikawa S, Suzuki T, et al. Effects of candesartan on cardiac sympathetic nerve activity in patients with congestive heart failure and preserved left ventricular ejection fraction. J Am Coll Cardiol 2005;45:661-7.

8. Kasama S, Toyama T, Kumakura H, Takayama Y, Ichikawa S, Suzuki T, et al. Effects of nicorandil on cardiac sympathetic nerve activity after reperfusion therapy in patients with first anterior acute myocardial infarction. Eur J Nucl Med Mol Imaging 2005;32:322-8.

9. Stone NJ, Robinson JG, Lichtenstein AH, Bairey Merz CN, Blum $\mathrm{CB}$, Eckel RH, et al. 2013 ACC/AHA guideline on the treatment of blood cholesterol to reduce atherosclerotic cardiovascular risk in adults: A report of the American College of Cardiology/ American Heart Association Task Force on Practice Guidelines. J Am Coll Cardiol 2014;63:2889-934.

10. Cholesterol Treatment Trialists C, Baigent C, Blackwell L, Emberson J, Holland LE, Reith C et al. Efficacy and safety of more intensive lowering of LDL cholesterol: A meta-analysis of data from 170,000 participants in 26 randomised trials. Lancet 2010;376:1670-81.

11. Pliquett RU, Cornish KG, Peuler JD, Zucker IH. Simvastatin normalizes autonomic neural control in experimental heart failure. Circulation 2003;107:2493-8.

12. Lee TM, Lin MS, Chang NC. Effect of pravastatin on sympathetic reinnervation in postinfarcted rats. Am J Physiol Heart Circ Physiol 2007;293:H3617-26.

13. Gao L, Wang W, Li YL, Schultz HD, Liu D, Cornish KG, et al. Simvastatin therapy normalizes sympathetic neural control in experimental heart failure: Roles of angiotensin II type 1 receptors and NAD(P)H oxidase. Circulation 2005;112:1763-70.

14. Host NB, Jensen LT, Bendixen PM, Jensen SE, Koldkjaer OG, Simonsen EE. The aminoterminal propeptide of type III procollagen provides new information on prognosis after acute myocardial infarction. Am J Cardiol 1995;76:869-73.

15. Authors/Task Force M, Catapano AL, Graham I, De Backer G, Wiklund O, Chapman MJ et al. 2016 ESC/EAS Guidelines for the Management of Dyslipidaemias: The Task Force for the Management of Dyslipidaemias of the European Society of Cardiology (ESC) and European Atherosclerosis Society (EAS) Developed with the special contribution of the European Assocciation for Cardiovascular Prevention \& Rehabilitation (EACPR). Atherosclerosis 2016;253:281-344.

16. Catapano AL, Reiner Z, De Backer G, Graham I, Taskinen MR, Wiklund $\mathrm{O}$, et al. ESC/EAS Guidelines for the management of dyslipidaemias The Task Force for the management of dyslipidaemias of the European Society of Cardiology (ESC) and the European Atherosclerosis Society (EAS). Atherosclerosis 2011;217:3-46.

17. Weintraub WS. Perspective on trends in statin use. JAMA Cardiol 2017:2:11-2.

18. Harrison TN, Hsu JY, Rosenson RS, Levitan EB, Muntner P, Cheetham TC, et al. Unmet patient need in statin intolerance: the clinical characteristics and management. Cardiovasc Drugs Ther 2018;32:29-36.

19. Bays H, Gaudet D, Weiss R, Ruiz JL, Watts GF, Gouni-Berthold I, et al. Alirocumab as add-on to atorvastatin versus other lipid treatment strategies: Odyssey options I randomized trial. J Clin Endocrinol Metab 2015;100:3140-8.

20. Weintraub WS, Gidding SS. PCSK9 inhibitors: A technology worth paying for? Pharmacoeconomics 2016;34:217-20.

21. Thackeray JT, Bengel FM. PET imaging of the autonomic nervous system. Q J Nucl Med Mol Imaging 2016;60:362-82.

22. Raffel DM, Jung YW, Koeppe RA, Jang KS, Gu G, Scott PJH, et al. First-in-human studies of [(18)F] fluorohydroxyphenethylguanidines. Circ Cardiovasc Imaging 2018;11:e007965.

23. Chen X, Fritz A, Werner RA, Nose N, Yagi Y, Kimura H, et al. Initial evaluation of AF78: A rationally designed fluorine-18-labelled PET radiotracer targeting norepinephrine transporter. Mol Imaging Biol 2019. https://doi.org/10.1007/s11307-019-01407-5.

24. Werner RA, Chen X, Maya Y, Eissler C, Hirano M, Nose N, et al. The impact of ageing on 11C-hydroxyephedrine uptake in the rat heart. Sci Rep 2018;8:11120.

25. Thackeray JT, Renaud JM, Kordos M, Klein R, Dekemp RA, Beanlands RS, et al. Test-retest repeatability of quantitative cardiac 11C-meta-hydroxyephedrine measurements in rats by small animal positron emission tomography. Nucl Med Biol 2013;40:676-81.

26. Werner RA, Rischpler C, Onthank D, Lapa C, Robinson S, Samnick S, et al. Retention kinetics of the 18F-labeled sympathetic nerve PET tracer LMI1195: Comparison with 11Chydroxyephedrine and 123I-MIBG. J Nucl Med 2015;56:1429-33.

27. Bengel FM. Imaging targets of the sympathetic nervous system of the heart: Translational considerations. J Nucl Med 2011;52:116770 .

Publisher's Note Springer Nature remains neutral with regard to jurisdictional claims in published maps and institutional affiliations. 